\title{
Wash fastness improvement of malachite green-dyed cotton fabrics coated with nanosol composites of silica-titania
}

\author{
I KARTINI $^{1 *}{ }^{*}$, I ILMI ${ }^{1}$, E S KUNARTI ${ }^{2}$ and KAMARIAH ${ }^{3}$ \\ ${ }^{1}$ Functional Coating Materials Research Group, Department of Chemistry, FMIPA, Universitas Gadjah Mada, \\ Sekip Utara, Yogyakarta 55281, Indonesia \\ ${ }^{2}$ Department of Chemistry, FMIPA, Universitas Gadjah Mada, Sekip Utara, Yogyakarta 55281, Indonesia \\ ${ }^{3}$ Faculty of Industrial Engineering, Universitas Islam Indonesia, Yogyakarta, Indonesia
}

MS received 23 December 2012; 14 March 2013

\begin{abstract}
Washing fastness of dyed cotton fabrics by malachite green (MG) blended with nanosols composite of $\mathrm{SiO}_{2}-\mathrm{TiO}_{2}$ has been significantly enhanced. The nanoparticulate inorganic sols were prepared by acidcatalyzed hydrolysis of titanium (IV) tetraisopropoxide (TTIP) and tetraethylortosilicate (TEOS) in ethanol at room temperature. The effect of silica on the characteristics of nanosols composite of $\mathrm{TiO}_{2}-\mathrm{SiO}_{2}$ was studied. Nanosols morphology was examined by transmission electron microscope (TEM). The nanosols silica-titania composite showed homogeneous morphology of interconnected spheres of about 20-25 nm. Enhanced dye absorption was observed at nanosols with silica content. The reflection spectra of the samples before and after leaching test using sodium dodecyl sulphate were recorded. The results showed that embedding $\mathrm{TiO}_{2}-\mathrm{SiO}_{2}$ and $\mathrm{SiO}_{2}$ sols into the MG dye can improve the wash fastness by $40-95 \%$. The highest improvement was obtained by $\mathrm{SiO}_{2}-\mathrm{MG}$-coated cotton fabrics as well as composites of $\mathrm{SiO}_{2}-\mathrm{TiO}_{2}-\mathrm{MG}$-dyed cotton fabrics at highest silica content. The MG-nanosols composite silica-titania dyed cotton fabric has also shown remarkable antibacterial activity over Staphylococcus aureus and Escherichia coli.
\end{abstract}

Keywords. Triphenylmethane dye; functional coating; leaching fastness; antibacterial; nanosols silica-titania.

\section{Introduction}

Dyeing is an important process in textile industries; therefore, efforts to improve wash and light fastness of the dyed textile are highly studied. One of the typical dyes for textiles is triphenylmethane dyes such as malachite green (MG) and guinea green (GG). They both have been commonly known as textile dyes which have low light and washing (leaching) fastness properties (Mahltig et al 2005a; Mahltig and Textor 2006). Today, they are mainly applied to dye polyacrylic fabrics. The structure of the polymer enables the electrovalence interaction resulting in strong dye adherence to the fabrics. Contrary, cellulose based fabrics, such as cotton, does not have sufficient affinity to those dyes (Mahltig et al 2004a, b).

Recent studies have shown the improvement of light and wash fastness properties of dyed cotton fabrics by incorporating the dyes into the sol-gel matrices of silica (Min et al 2003; Mahltig et al 2005a; Mahltig and Textor 2006). They have shown that improved wash fastness can be obtained by modifying the dye sols composition. Mahltig et al (2005b) has studied that incorporating $\mathrm{UV}$-absorber such as $\mathrm{TiO}_{2}$ combined with organic UV absorber such as Tinuvin 213 improved the UV-protecting

*Author for correspondence (indriana@ugm.ac.id) properties of the resulting layers on glass. Optimized UV-protecting coatings by the presence of titania and organic UV absorbers were achieved at a certain composition. Yadav et al (2006) has shown the incorporation of zinc oxide nanoparticles on bleached cotton fabrics providing UV-blocking properties. Thus, it is interesting to apply such nanosols composite of silica-titania to the dyed cotton fabrics. It is necessary to study the effect of the nanosols composite on the wash fastness of the dyed fabrics. Instead, the fabrics will have UV protection as well as antimicrobial properties.

The present study concerns the preparation and optimization of the silica-titania nanosols composite coating to improve the wash fastness of MG-dyed cotton fabrics. The nanosols are mixed directly with the dyes and used as dye precursors. Details on nanosols characterization are reported. Nano-size features of both silica and titania nanosols are predicted to enhance the wash fastness of the MG-dyed cotton fabrics. It will be shown that the presence of titania may result in lowering the wash fastness of the dyed cotton fabrics. However, a combination of inorganic nanosols composite of silica and titania is needed to get other functional coating, such as UV protection and antimicrobial activity. Thus, optimized composition of silica-titania nanosols will be recommended. Our investigation also revealed the presence of 
Table 1. Mixing chemical compositions of the nanosols.

\begin{tabular}{lcccc}
\hline $\mathrm{Mole} \mathrm{ratio} \mathrm{of}_{\mathrm{SiO}_{2}-\mathrm{TiO}_{2}}$ & TEOS $(\mathrm{mL})$ & TTIP $(\mathrm{mL})$ & Ethanol $(\mathrm{mL})$ & $\mathrm{HCl} 1 \mathrm{M}(\mathrm{mL})$ \\
\hline $1: 1$ & 20 & 20 & 280 & 7 \\
$2: 1$ & 40 & 20 & 260 & 7 \\
$3: 1$ & 60 & 20 & 240 & 7 \\
$1: 0$ & 20 & 0 & 300 & 7 \\
$0: 1$ & 0 & 20 & 300 & 7 \\
\hline
\end{tabular}

nanoscale spherical particulates in the nanosols composite with interconnected linkages.

\section{Experimental}

\subsection{Nanosols preparation}

Silica and titania solutions were made through the hydrolysis of tetraethyl-orthosilicate (TEOS) and titanium (IV) tetra-isopropoxide (TTIP 98\%, $\rho=0.955$ ), respectively. The chemicals were purchased from Aldrich and used as received. The composite sols were prepared by mixing the two solutions into ethanol with mole ratio of $\mathrm{SiO}_{2}$ to $\mathrm{TiO}_{2}$ of $1: 1,2: 1$ and $3: 1$ as listed in table 1 . Hydrochloric acid (1 M) was added drop-wise into the sols of silicatitania. The nanosols were then stirred at room temperature for $24 \mathrm{~h}$ and readily used as coating precursors for the cotton fabrics. The nanosols were characterized by UV-Vis spectrophotometer (Genesys 20) and TEM (JEOL JEM 1400 at $120 \mathrm{kV}$ ). The dried gels of the corresponding nanosols at room temperature were subjected to characterization using infrared spectrophotometer (Shimadzu 8021) and XRD (Shimadzu XRD 6000 using $\mathrm{CuK} \alpha$ radiation). The infrared samples were prepared using $\mathrm{KBr}$ pellet method with scanning accumulated at a spectral resolution of $4 \mathrm{~cm}^{-1}$.

\subsection{Nanosols coating on cotton fabrics}

The cotton fabric was obtained from traditional market and was previously tested to contain fully cellulose fibres by fire-burning test. Dip-coating with withdrawn rate of $30 \mathrm{~cm} / \mathrm{min}$ (Mahltig and Textor 2006) was performed on cotton fabrics $\left(30 \times 50 \mathrm{~mm}^{2}\right)$ for 10 times coating using the nanosols ( $18 \mathrm{~g}$ into $90 \mathrm{~mL}$ of ethanol). The as-coated fabrics were then dried at room temperature and at $120^{\circ} \mathrm{C}$ for $1 \mathrm{~h}$. The coated cotton samples were characterized using XRD.

\subsection{Dyeing the cotton fabrics with nanosols composite of silica-titania and malachite green dye}

About $18 \mathrm{~g}$ of nanosols was mixed with $82 \mathrm{~mL}$ of ethanol. Then, the dye, $0.9 \mathrm{~g}$ of $\mathrm{MG}$ solution $(0.004 \mathrm{~g}$ in $10 \mathrm{~mL}$ ethanol), was mixed with the sols. The fabrics were then dip-coated into the dye-nanosols mixture, using the same procedure as previously used for nanosols coating on cotton fabrics.

\subsection{Leaching test}

The leaching test was performed using $1 \mathrm{wt} \%$ of aqueous solution of sodium dodecyl sulphate (SDS) (Mahltig and Textor 2006). The reflectance spectra of the fabrics after and before leaching were examined by reflectance spectrophotometer (Specular Reflectance Shimadzu UV 1700 Pharmaspec). The leaching degree $(D)$ was calculated using the equation $D=100(r A-r B) /(100-r B)$ (Mahltig and Textor 2006). $r B$ and $r A$ represent the reflectance before and after the leaching test, respectively. The values of $r B$ and $r A$ were taken at the most minimum wavelength of the reflection spectra of the dyed fabrics.

\subsection{Antibacterial test}

The antimicrobial effect of the coated cotton fabrics was tested against Staphylococcus aureus and Escherichia coli using Plate count method. A nutrient agar medium (g/L: peptone 5 ; beef extract 1.5 ; yeast extract $1.5 ; \mathrm{NaCl}$ 5; agar 20 and $\mathrm{pH} 7.5$ ) was prepared and autoclaved at $121{ }^{\circ} \mathrm{C}$ for $15 \mathrm{~min}$. Test organisms were grown overnight at $37^{\circ} \mathrm{C}$, in $10 \mathrm{~mL}$ of nutrient broth. The bacteria test Petri plates were incubated at $37^{\circ} \mathrm{C}$ for $72 \mathrm{~h}$. At the end of this period, zones of inhibition (ZOI) formed on the medium were measured in millimetres $(\mathrm{mm})$. The results are presented as the ratio of diameter of inhibition to the diameter of the coated cotton samples.

\section{Results and discussion}

\subsection{Nanosols preparation and characterization}

Silica, titania and the composite sols were prepared by sol-gel technique at $\mathrm{pH}$ around 5-6 under acid-catalysed hydrolysis at room temperature. Figure 1 shows the absorption spectra of silica, titania and silica-titania nanosols. All spectra exhibit similar pattern of single broad absorption peak indicating the occurrence of nanoparticulates as the sols building blocks. Similar absorption peak at around $230 \mathrm{~nm}$ was also observed for Ti-grafted 
MCM-48 (Morey et al 2000). The less intense absorption peaks of silica sols were presumably due to the presence of smaller particulates of silica than those of titania sols. Enhanced absorption was obtained as the silica sols were mixed with titania, confirming the additive properties of absorption spectra of the nanosols. The absorption decreases as the silica content increases. Absorption peak of the composite sols was also narrower than titania, indicating the contribution effect of the small silica particulates. Blueshifting absorption peak was observed as the silica content increased, indicating the presence of smaller particulates building blocks as the nanosol constituent.

The nano-sized particulate building blocks of the nanosols were confirmed by the representative TEM images of silica-titania nanosols as depicted in figure 2 . The particulates were spherical with diameters of about 20-25 nm (figure 2). Figure 2(a) shows that the spherical nanoparticulates are interconnected. The images also show that the size of particulates was homogeneous, providing better particle attachment to the cotton fibres. Thus, the composite sols can be called as nanosols, as coined by Mahltig et al (2005a).

The infrared spectra of the dried gels (figure 3 ) have confirmed the observed silica-titania interaction in the nanosol composites as indicated by their UV-Vis spectra. Vibrations at $\sim 1100$ and $1200 \mathrm{~cm}^{-1}$ (displayed as a shoulder) observed at $\mathrm{SiO}_{2}$ and $\mathrm{Si}-\mathrm{Ti}$ dried gels can be assigned to the asymmetric stretching of $\mathrm{Si}-\mathrm{O}-\mathrm{Si}$, while peaks at $\sim 820$ and small peak at $\sim 470 \mathrm{~cm}^{-1}$ can be attributed to the symmetric stretching and deformation modes of $\mathrm{Si}-\mathrm{O}-\mathrm{Si}$, respectively (Dutoit et al 1995; Hutter et al 1995). The $\mathrm{Si}-\mathrm{Ti}$ composite gels present vibrations at $950 \mathrm{~cm}^{-1}$, suggesting to the distorted $\mathrm{Si}-\mathrm{O}$ tetrahedron due to the formation of $\mathrm{Ti}-\mathrm{O}-\mathrm{Si}$ bonds (Boccuti et al 1989;

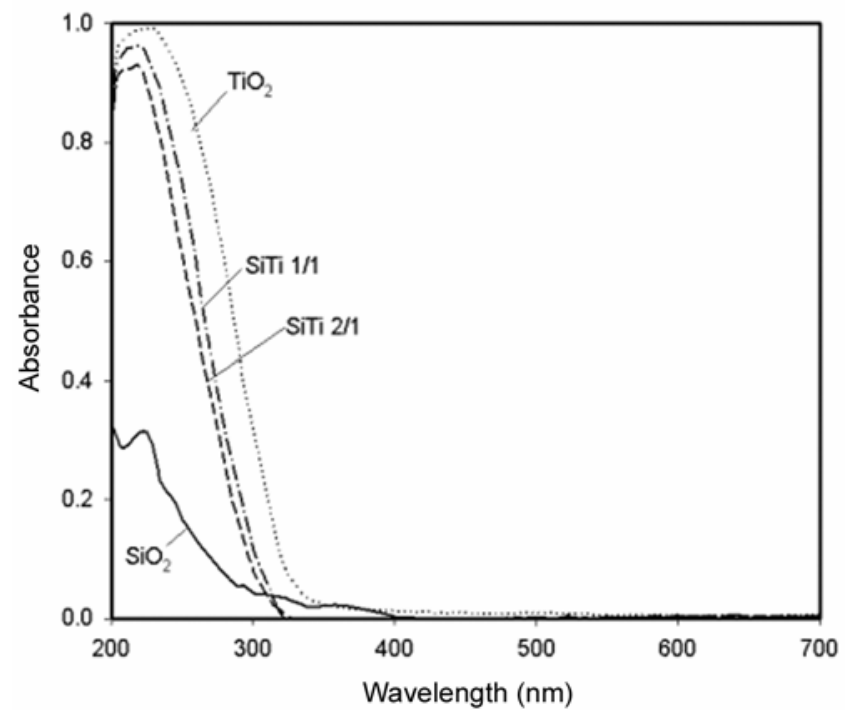

Figure 1. Absorption spectra of silica $\left(\mathrm{SiO}_{2}\right)$, titania $\left(\mathrm{TiO}_{2}\right)$, and silica-titania ( $\mathrm{SiTi}$ ) nanosols.
Dutoit et al 1995; Hutter et al 1995; Galan-Fereres 1995; Navarrete et al 1996; Seco et al 2000). Similar phenomenon has been observed for the formation of titania-silica hydrophobic xerogels (Mariscal et al 2000). The silicatitania material has a hydrophilic surface. It is generally accepted that water adsorbed on the silica or titania surface due to the formation of hydrogen bonding with silanol $(\equiv \mathrm{Si}-\mathrm{OH})$ or titanol $(\equiv \mathrm{Ti}-\mathrm{OH})$ groups (Mariscal et al 2000; Nizar et al 2013). Thus, water adsorption should be related to the number of $-\mathrm{OH}$ group at the silica or titania surface. The more the number of $-\mathrm{OH}$ groups, the more hydrophilic the surface. Infrared spectra identify the $-\mathrm{OH}$ groups as broad stretching vibrations of $\mathrm{O}-\mathrm{H}$
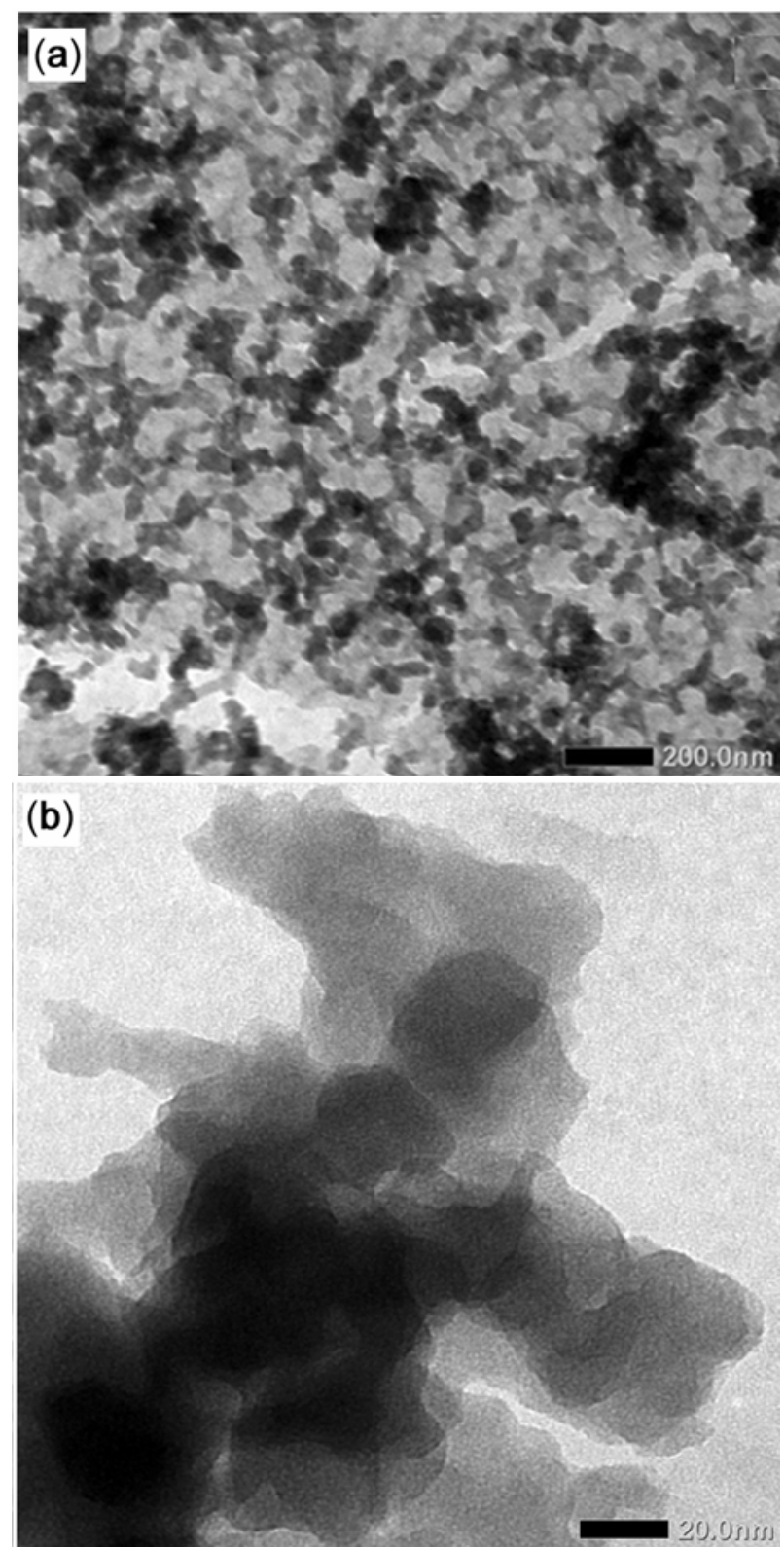

Figure 2. TEM images of silica-titania nanosols at lower (a) and higher magnifications (b). 
(hydrogen-bonded surface silanols) at $\sim 3500 \mathrm{~cm}^{-1}$ and bending at $\sim 1630 \mathrm{~cm}^{-1}$. The first vibration actually includes the contribution of all hydroxyl-containing species, whereas $\mathrm{O}-\mathrm{H}$ stretching of free water is observed as a small peak at $\sim 3700 \mathrm{~cm}^{-1}$ (Mariscal et al 2000). It is also observed that broadband around $\sim 3500 \mathrm{~cm}^{-1}$ of $\mathrm{Si}-\mathrm{Ti}$ dried gel are less pronounced compared to that of $\mathrm{TiO}_{2}$ indicating reduced hydrophilicity of titania surfaces as the silica interacted with titania. This is in agreement with findings of several other researches for silica-titania prepared from TEOS and TTIP (Zhou et al 1996; Mariscal et al 2000; De Paz et al 2012; Nizar et al 2013). The decreased intensity of the $\mathrm{O}-\mathrm{H}$ vibrations might be due to the formation $\equiv \mathrm{Si}-\mathrm{O}-\mathrm{Ti} \equiv$ bond (Nizar et al 2013). Even the hydrophilicity of $\mathrm{TiO}_{2}$ dried gels was slightly removed as interacted with $\mathrm{SiO}_{2}$, the nanoparticles aggregation on the corresponding nanosol was still observed (figure 2a), resulting in more interconnected nanoparticulates. This feature will provide a strong attachment of dye molecules that can be entrapped in interstitial voids between particulates, leading to the low degree of leaching of the attached dye on cotton fabrics.

\subsection{Nanosols-coated cotton fabrics characterization}

Figure 4 displays the XRD pattern of the nanosols-coated cotton fabrics. It is observed that all patterns show the reflection peaks of cellulose (Vainio 2007). The diffraction pattern of pristine cotton exhibited typical reflection peaks of native cellulose at $14^{\circ}\left(d_{101}\right), 16^{\circ}\left(d_{10 \overline{1}}\right), 22.5^{\circ}$ $\left(d_{002}\right)$ and $34^{\circ}\left(d_{040}\right)$, indicating predominantly celluloseI $\beta$ (Wada et al 2001; Lee et al 2012). The intensity of cellulose reflections is getting stronger as the fabrics coated by sols containing silica, but they are weaker for $\mathrm{TiO}_{2}$ nanosols-coated fabrics. It is supposed that titania

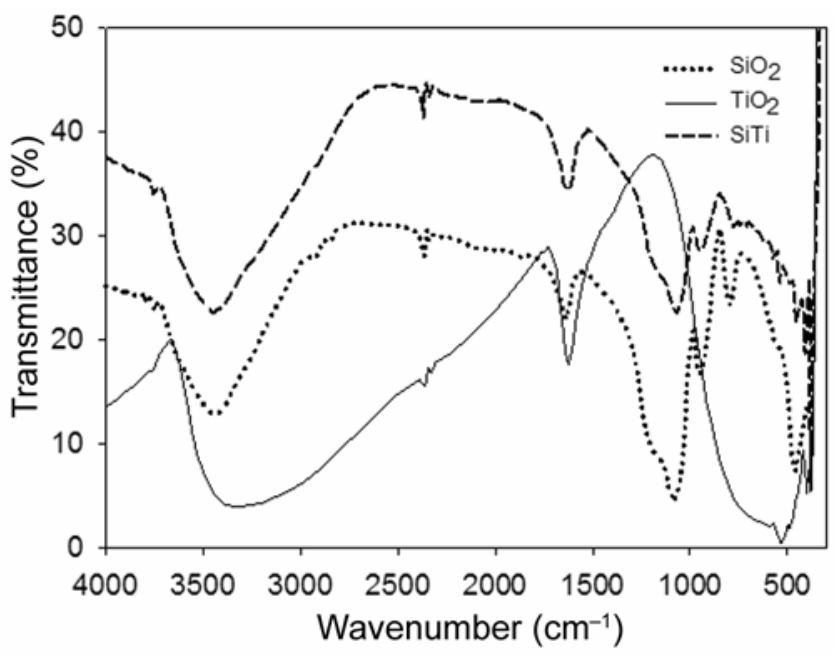

Figure 3. Infrared spectra of silica $\left(\mathrm{SiO}_{2}\right)$, titania $\left(\mathrm{TiO}_{2}\right)$ and silica-titania (SiTi) dried gels. nanosols coat the fibres strongly than silica, resulting in more uniform and possibly thicker coating leading to enhanced intensity of cellulose reflections. This behaviour may also lead to stronger dye attachment of the composition of silica nanosols-MG onto the cotton surfaces than titania nanosols-MG. Moreover, the coating of silicatitania nanosols composite will have moderate adherence to the cotton fibres. The XRD patterns of the hydrogel of the corresponding nanosols (Kunarti et al 2012) showed that silica and titania retain the amorphous nature of their structure, while titania has slightly increased its crystallinity in the presence of silica. However, the titania is still amorphous. No crystalline polymorph of titania was detected on the corresponding hydrogels. Hence, probable photocatalytic degradation of the coated dye by the presence of photoactive titania polymorph such as anatase or rutile can be hindered. Whereas the amorphous nature of silica and titania is expected to provide more $-\mathrm{OH}$ surfaces beneficial for linking via hydrogen bonding with cellulose surface. In turn, it will increase the sols adherence to the surface of cotton fabrics. The proposed interaction between the cotton fabric and the silica-titania nanosols is illustrated in figure 5 .

\subsection{Characterization of MG-nanosols and the corresponding coated cotton fabrics}

Figure 5 shows the absorption spectra of MG dye solution and the dye precursors of $\mathrm{MG}$ with nanosols of silica, titania and silica-titania composite. The dye characteristic is shown by the appearance of a sharp peak at $620 \mathrm{~nm}$ (Mahltig and Textor 2006) with three weaker absorptions

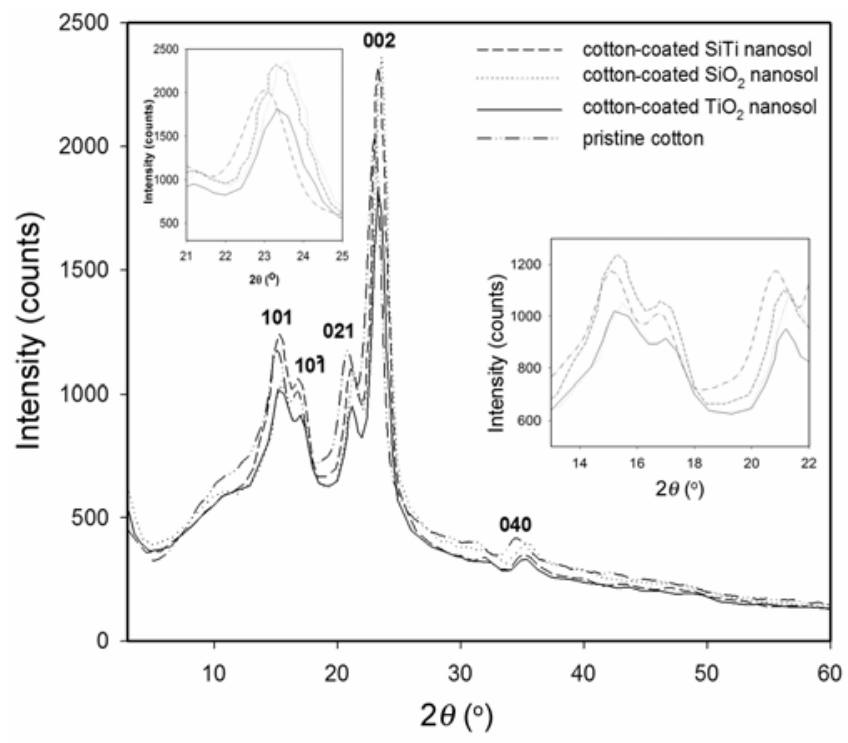

Figure 4. XRD patterns of the pristine cotton fabrics and cotton fabrics coated with silica nanosol, titania nanosol and silica-titania nanosols composite. 
at 320,430 and $550 \mathrm{~nm}$. The absorptions are due to electron transitions from $n$ to $\sigma^{*}$ of the chromophores and from $\pi$ to $\pi^{*}$ of the benzene ring of the dye structure. Proposed interaction between the MG and the composite silica-titania nanosols has also been illustrated in figure 5. The surface of silica sol particulates has been known to be negatively charged in a broad $\mathrm{pH}$ range $(\mathrm{pH}>2)$ (Park et al 2006). The negative sites will interact readily with the cationic nature of MG dyes. Cationic MG is supposed to interact with the nanosols via direct electrostatic attraction to the silica matrix (Mahltig et al 2004b).

It can be seen from the spectra (figure 6) that increased intensity is apparent for the absorption spectrum of dye precursor containing silica nanosols only due to the preferred interaction between the dye and negatively charged silica nanosols. The presence of titania nanoparticle is also obvious from the existence of broad absorption around

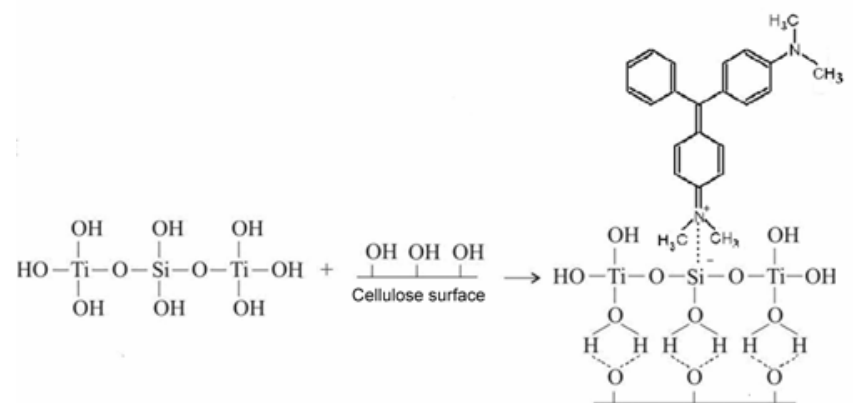

Figure 5. Illustration of the proposed interaction among the cotton fabric, the malachite green dye and the silica-titania nanosols.

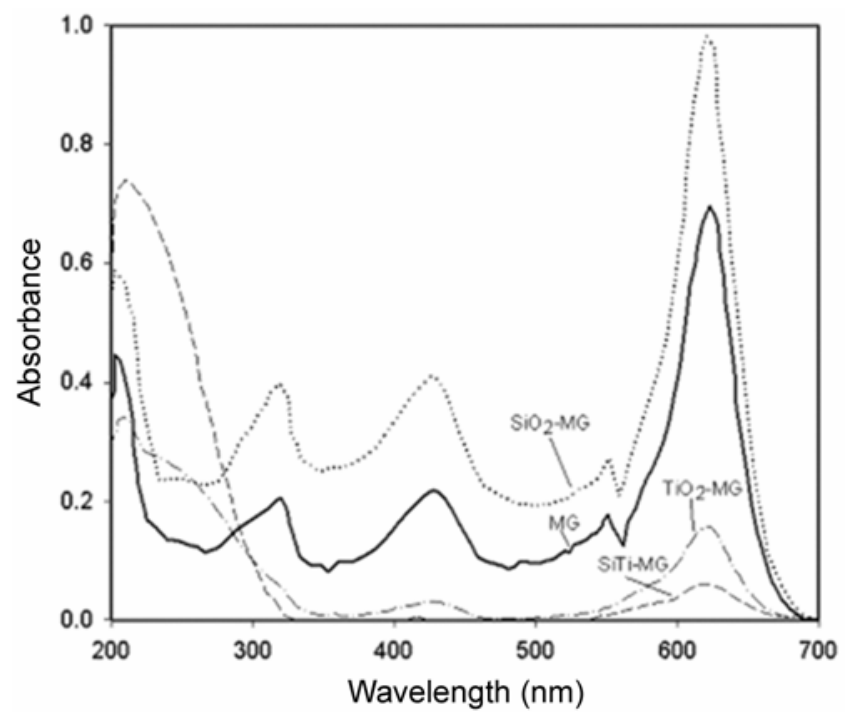

Figure 6. Absorption spectra of malachite green dye solution (MG) and MG-dye combined with silica nanosol $\left(\mathrm{SiO}_{2}-\mathrm{MG}\right)$, titania nanosol $\left(\mathrm{TiO}_{2}-\mathrm{MG}\right)$, and silica-titania nanosols composite (SiTi-MG).
200-300 nm. The broad absorption bands have been confirmed previously in figure 1 as the characteristic of titania electronic absorption. Lower absorptions of the dye in precursors containing titania $\left(\mathrm{TiO}_{2}-\mathrm{MG}\right.$ and $\left.\mathrm{SiTi}-\mathrm{MG}\right)$ are presumably caused by the weaker interaction between the dye and $\mathrm{TiO}_{2}$, which has more positive surface potential compared to $\mathrm{SiO}_{2}$ particle (Park et al 2006).

Figure 7 shows the reflectance spectra of MG-nanosols dyed cotton fabrics. The dye characteristic is shown by the appearance of the minimum of the reflectance spectra at $620 \mathrm{~nm}$ (Mahltig and Textor 2006). It is clear that the peak positions of the dye do not change as the dye interact with the silica-titania nanosols and adsorbed on the cotton fabrics. But the peaks are broader than the corresponding peaks in the solution (figure 6). It is assumed that there is a strong interaction between the surfaces and the adsorbed molecules that often lead to the aggregation effect (Kamat 1993).

\subsection{Wash fastness}

The results of the leaching test are depicted in figure 8 . The graph shows that MG-dyed cotton fabrics without nanosols coating have the highest degree of leaching at around $45 \%$. High wash fastness improvement of $\sim 95 \%$ was achieved for cotton fabrics dyed with $\mathrm{MG}-$ silica and MG-SiTi $(3: 1)$. It is also observed that MG-titania nanosols-dyed cotton fabrics have only a small improvement of the wash fastness of the dye $(\sim 40 \%)$. The increased dye leaching is supposed to be the effect of the photocatalytic activity of titania nanoparticles (Jiang et al 2008). Even in the less crystalline anatase form, titania may still exhibit photoactivity to degrade the dye (Bozzi et al 2005). Hence, the nanosols composite generated

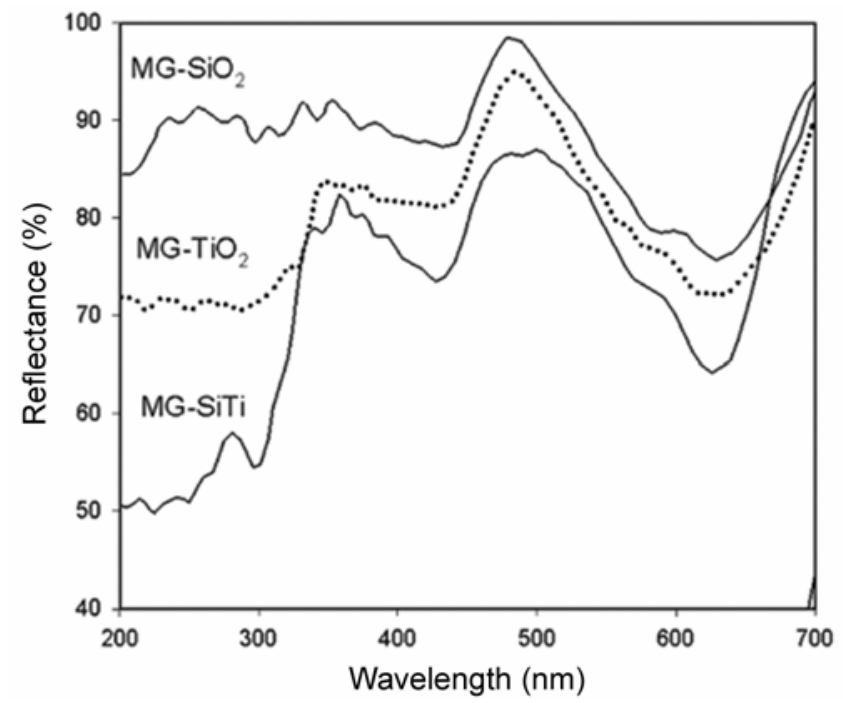

Figure 7. The reflectance spectra of MG-nanosols dyed cotton fabrics. 
higher wash fastness improvement than those of MG-dyed without nanosols and MG-titania nanosols-dyed cotton fabrics due to the presence of silica. Hydrolyzed metal alkoxide solutions have been proven as an excellent tool to convey new properties to the cellulosic materials (Schramm et al 2005).

Another important feature of dyeing is the drying temperature. From figure 8 , it can be seen that dyed cotton fabrics dried at $120{ }^{\circ} \mathrm{C}$ exhibit better wash fastness than those dried at room temperature. A strong adherence of the coating materials is likely to occur at high drying temperature in a similar manner of annealing leading to the lower degree of leaching.

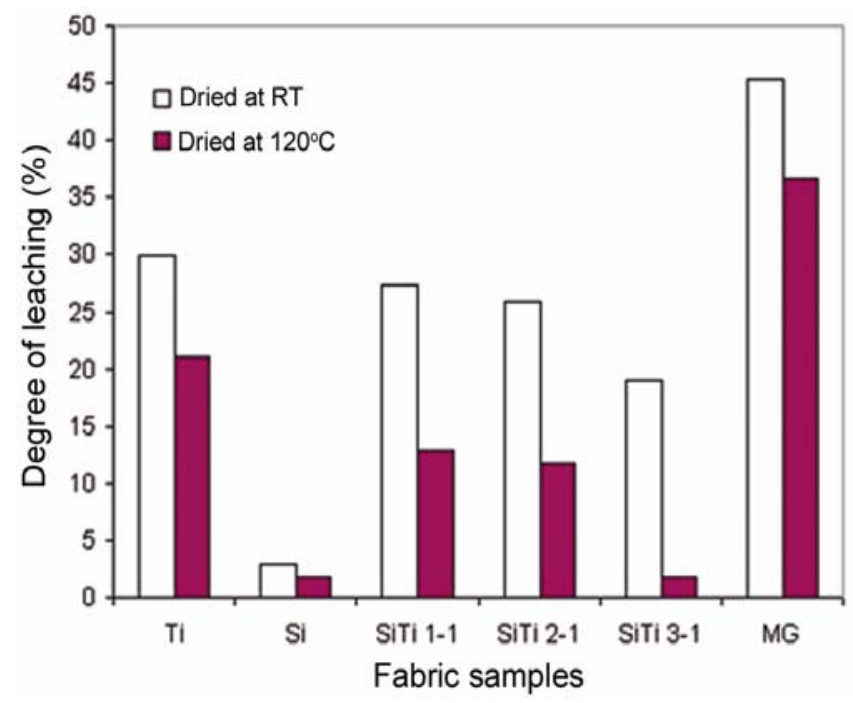

Figure 8. Wash fastness of the dyed cotton fabrics (MG) and functionalized dyed cotton fabrics at various $\mathrm{Si}$ : Ti nanosols composition.

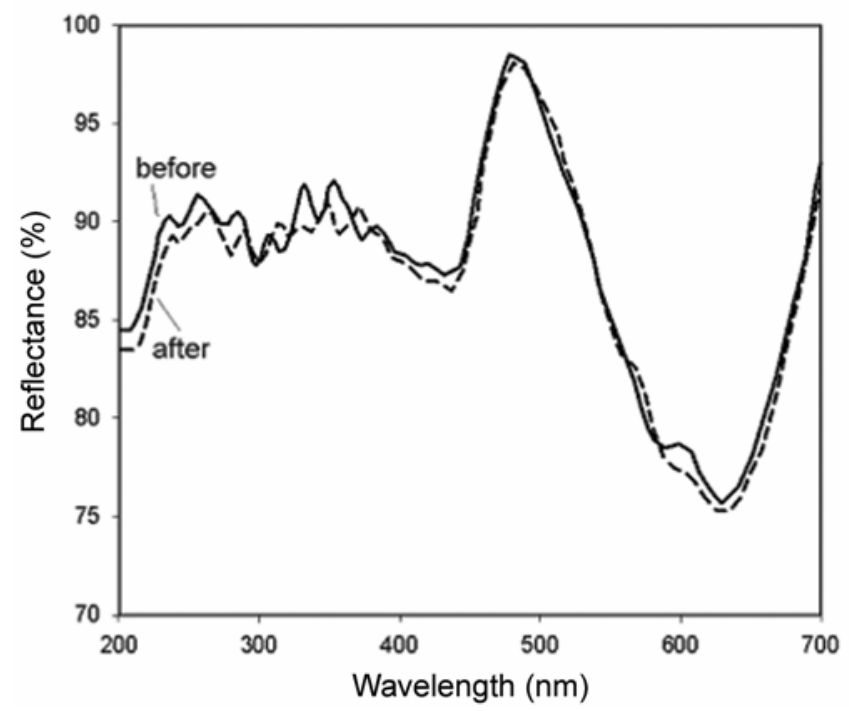

Figure 9. Reflectance spectra of the MG-dyed cotton fabrics coated with silica nanosols: before and after leaching test.
The reflectance spectra of the MG-silica, MG-titania and $\mathrm{MG}$-silica titania composite nanosols dyed after and before leaching test as depicted in figures 9-11, respectively, show a clear evidence of the wash fastness improvement of dyeing the cotton fabrics using dye precursors containing nanosols of silica and the composite with titania. The absorption of the dye, which is the minimum of the reflectance spectra, at around $620 \mathrm{~nm}$, is reduced strongly for the dyed MG-titania nanosols. Significant improvement is achieved when introducing silica nanosols into the composites. However, titania can still be used in the nanosol composite in certain limited

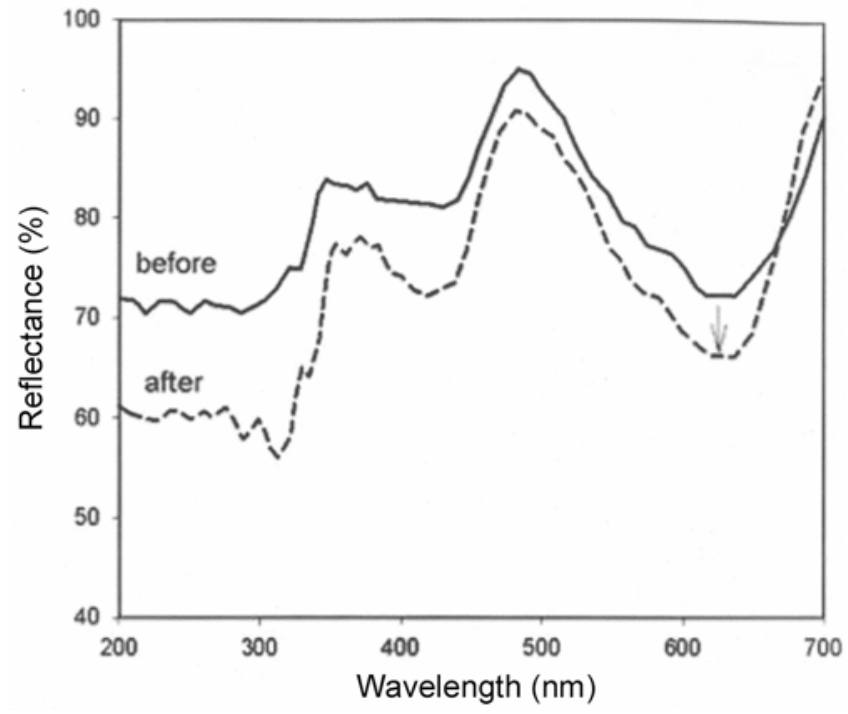

Figure 10. Reflectance spectra of the MG-dyed cotton fabrics coated with titania nanosols: before and after leaching test.

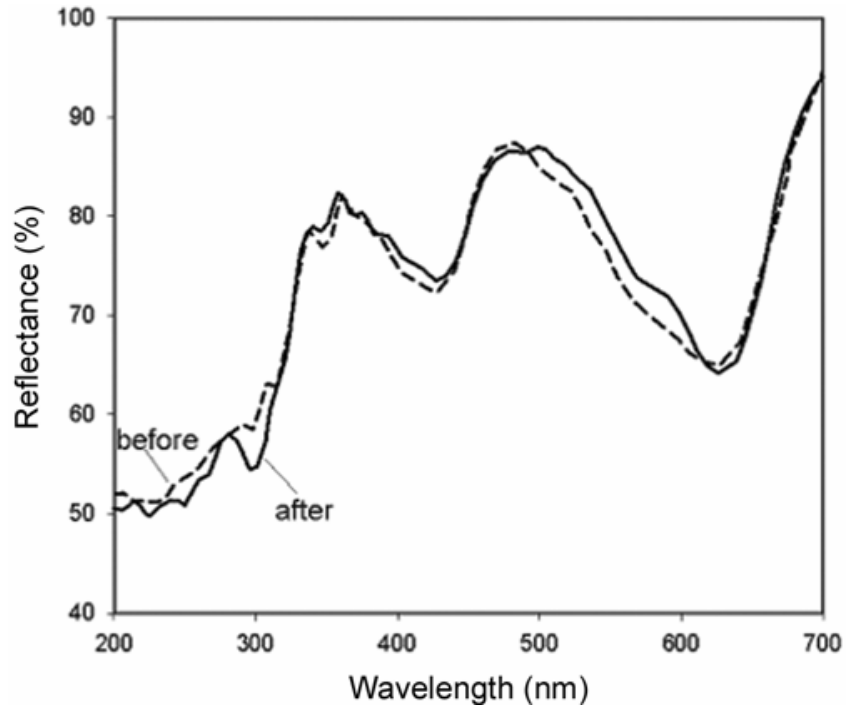

Figure 11. Reflectance spectra of the MG-dyed cotton fabrics coated with composite nanosols of silica-titania (3/1): before and after leaching test. 
Table 2. Antibacterial activity.

\begin{tabular}{lcc}
\hline & \multicolumn{2}{c}{$\begin{array}{c}\text { Diameter ratio of ZOI to fabric's } \\
\text { diameter }\end{array}$} \\
\cline { 2 - 3 } Samples & S. aureus & E. coli \\
\hline Cotton fabric & 1.00 & 1.00 \\
SiTi-coated cotton & 1.00 & 1.00 \\
SiTi-MG-dyed cotton & 3.85 & 3.78 \\
\hline
\end{tabular}

amount. The mole ratio of silica to titania of $3: 1$ is the recommended formulation for nanosols blended with MG-dye as the dye-sols precursor. Considering high mechanical and stability of silica, higher silica content is hindered due to the increased toughness of the cotton fabrics.

\subsection{Antibacterial activity}

Cotton fabrics are the most susceptible substrates for the settling of microorganisms, since they provide large specific surfaces with good adhesion and water absorption. Therefore, it is necessary to have functional cotton fabrics with antimicrobial finishes. In this research, the MG-dyed nanosols-coated cotton fabrics were tested over Gram-positive bacteria (S. aureus) and Gram-negative bacteria (E. coli) using Plate count method. The results are listed in table 2 .

From table 2, it is clear that the MG-dyed cotton fabrics coated with silica-titania nanosols composite showed antibacterial activities towards both bacteria. The SiTi-coated cotton only exhibits antibacterial activity on the surface of the cotton, while the dyed one has inhibitory effect in larger area over the surface of the cotton. The nanoparticle oxides affect the cell physiological activities by interacting with lipopolysaccharide and lipoteichoic acid through hydrogen bonding and ligand exchange. Bacterial toxicity of nanoparticle oxides is more likely due to protein structural changes and phospholipid molecular damage (Jiang et al 2010; Jisha et al 2012). The changes are possibly causing the loss of the cell membrane integrity and the leakage of the periplasm. Damage to phospholipid structure, henceforth, the cell membrane, may lead to bacterial cell death. The dye itself has already been known to have antibacterial properties due to its cationic nature (Tutak and Gun 2012). Electrostatic interaction between positively charged nitrogen and the predominantly anionic components of the microorganisms surface (such as Gram-negative lipopolysaccharide and cell surface proteins) plays a primary role in antibacterial activity. This property leads to almost 4 times higher antibacterial activity for SiTi-MG dyed cotton. It is noteworthy that blending the nanosols with MG dye resulted in synergistic effect of high wash fastness and antibacterial activity.

\section{Conclusions}

The role of silica-titania, titania and silica nanosols to improve the wash fastness of the dye on the cotton fabrics has been presented. Wash fastness improvement was obtained using dye precursors containing high silica content. It is clear that silica supports the dye attachment due to its amorphous, nano-sized features and its surface nature. While titania weakens the dye attachment, probably due to its photocatalytic activity. The cotton fabrics dyed with MG solution containing nanosols composite of silica-titania at a mole ratio of $3: 1$ has also shown remarkable antibacterial activity toward Gram-positive bacteria (S. aureus) and Gram-negative bacteria (E. coli).

\section{Acknowledgement}

The authors acknowledge financial support of DP2M, Directorate General of Higher Education, Indonesia, through research grant of multidisciplinary research under decentralization scheme of Universitas Gadjah Mada (LPPM-UGM/704/BID.I/2012). Thanks are extended to Ms Kholilah for some experimental works.

\section{References}

Boccuti M R, Rao K M, Zecchina A, Leofanti G and Petrini G 1989 Stud. Surf. Sci. Catal. 48133

Bozzi A, Yuranova T, Laub D, Kiwi J and Guasaquillo I 2005 J. Photochem. Photobiol. A: Chem. 174156

De Paz H, Chemtob A, Croutxe-Barghorn C, Le Nouen D and Rigolet S 2012 J. Phys. Chem. B116 5260

Dutoit D C M, Schneider M and Baiker A 1995 J. Catal. 153 165

Galan-Fereres M, Alemany L J, Mariscal R, Banares M A, Anderson J A and Fierro J L G 1995 Chem. Mater. 71342

Hutter R, Mallat T and Baiker A 1995 J Catal. 153177

Jiang D, Xu Y, Wu D and Sun Y 2008 J. Solid State Chem. 181 593

Jiang W, Yang K, Vachet R W and Xing B 2010 Langmuir 26 18071

Jisha E R, Balamurugan G, Selvakumar P, Edison N and Rathiga R 2012 Internat. J. Pharm. Tech. Res. 41323

Kamat P V 1993 Chem. Rev. 93267

Kunarti E S, Kartini I, Kamariah and Kholilah 2012 unpublished results

Lee K-Y, Tammelin T, Schulfter K, Kiiskinen H, Samela J and Bismarck A 2012 ACS Appl. Mater. Interfaces 44078

Mahltig B and Textor T 2006 J. Sol-Gel. Sci. Technol. 39114

Mahltig B, Bottcher H, Knittel D and Schollmeyer E 2004a Text Res. J. 74521

Mahltig B, Knittel D, Schollmeyer E and Bottcher H 2004b J. Sol-Gel. Sci. Technol. 31293

Mahltig B, Bottcher H, Rauch K, Diekmann U, Nische R and Fritz T 2005a Thin Solid Films 485108

Mahltig B, Helfried H and Bottcher H 2005b J. Mater Chem. 15 4385 
Mariscal R, López-Granados M, Fierro J L G, Sotelo J L, Martos C and van Grieken R 2000 Langmuir 169460

Min L, Xiaoli Z and Shuilin C 2003 Coloration Technol. 119 297

Morey M S, O'Brien S, Schwarz S and Stucky G D 2000 Chem. Mater. 12898

Navarrete J, Lopez T, Gomez R and Figueras F 1996 Langmuir 124385

Nizar U K, Efendi J, Yuliati L, Gustiono D and Nur H 2013 Chem. Eng. J. 22223

Park J H, Yang, J H, Yoon J B, Hwang S J and Choy J H 2006 J. Phys. Chem. B110 1592
Schramm C, Rinderer B, Binder W H, Tessadri R and Duelli H 2005 J. Mater. Sci. 401883

Seco A M, Goncalves M C and Almeida R M 2000 Mater. Sci. Eng. B76 193

Tutak M and Gun F 2012 TEKSTILL ve KONFEKSIYON 2248 Vainio U 2007 Report Series Phys: HU-P-D145 (Finlandia: Helsinki University Printing House)

Wada M, Okano T and Sugiyama J 2001 J. Wood Sci. 47124

Yadav A, Prasad V, Kathe A A, Raj S, Yadav D, Sundaramoorthy C and Vigneshwaran N 2006 Bull. Mater. Sci. 29641

Zhou Q F, Zhang Q Q, Zhang J X, Zhang L Y and Yao X 1996 Mater. Lett. 3139 